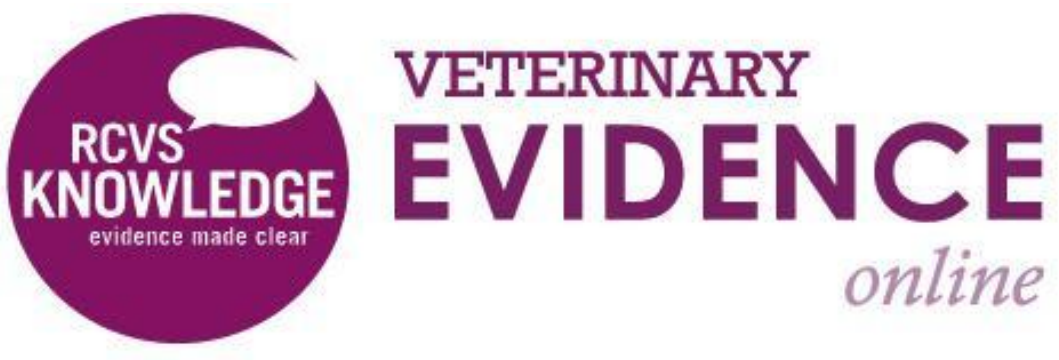

\title{
A Guide for Students and Staff (Thinking of) Doing Systematic Reviews
}

Nieky van Veggel MSc, CBiol, FHEA ${ }^{1^{*}}$

${ }^{1}$ School of Sport, Equine and Animal Science, Writtle University College, Lordship Road, Chelmsford, Essex, CM1 3RR, United Kingdom

Corresponding Author (Nieky.VanVeggel@writtle.ac.uk)

ISSN: 2396-9776

Published: 03 Jan 2018

in: Vol 3, Issue 1

DOI: http://dx.doi.org/10.18849/ve.v3i1.161 
More and more students on a variety of higher education courses are performing systematic reviews as part of their independent research, and it is becoming more common for research students to undertake a systematic review as part of their thesis or dissertation.

Although plenty of guidance is available in the form of books, paper collections and online advice, the majority of currently available sources are aimed at health care practitioners and researchers rather than students in general. Writing for students requires a clear narrative and a more accessible writing style, this gap was addressed by the first edition of this book published in 2014. However, systematic review as a method of research has evolved rapidly, and expanded into more and more fields. The publication of a second edition, with a new student-friendly 10-step roadmap, more comprehensive coverage of qualitative systematic reviews and a chapter on disseminating review findings was justified. In addition, in line with many other studentfocussed textbooks, the new edition is now supported by online resources which aid in understanding the systematic review process.

Starting with an introduction to carrying out a systematic review as a student, the authors cover the whole process from planning and defining the question, to data synthesis and writing a discussion. In addition, chapters on specific aspects of reviewing qualitative and economic evidence and guidance on the dissemination of reviews makes this a well-rounded textbook.

The strongest feature of this book is its use of clear examples supported by "frequently asked questions" sections. The combination of these approaches allows for a very unthreatening journey that is the production of a systematic review. Most, if not all, common questions received by supervisors from students undertaking systematic review projects have been addressed, which will make students more confident when discussing their work with supervisors. Furthermore, the student-friendly language of this book makes for engaging reading. The authors have chosen to address the reader throughout the book, rather than opting for a more neutral writing style. Keeping in mind the target audience and the aim of the book, this style helps maintain the reader's interest (Treagust and Harrison, 1999).

A possible improvement to this book would be a more thorough introduction to realist reviews. Where in many cases systematic reviews are the most appropriate way forward for knowledge synthesis, the complex areas of evidence-based policy making and social interventions calls for a more "realist approach" to evaluation (Pawson et al., 2005). However, as realist synthesis warrants a book in its own right, and is possibly not appropriate for master's level research, this gap is forgivable and does not diminish the contribution that Doing a Systematic Review makes to student systematic review research and learning.

To conclude, Doing a Systematic Review is the book of choice for all students and early career researchers who are considering or undertaking systematic review research, and makes a valuable teaching resource for all academic staff in areas of evidence-based practice. 
Nieky van Veggel received a copy of this book as a free inspection copy as per standard academic practice, but reports no other conflicting interests and was not involved in the conception of this book or its previous edition.

\section{REFERENCES}

1. Boland, A., Cherry, M.G. and Dickson, R. (Eds.) (2017) Doing a Systematic Review - a student's guide ( ${ }^{\text {nd }}$ edition), London: Sage. pp. 275 .

2. Pawson, R., Greenhalgh, T., Harvey, G., Walshe, K. (2005) Realist review - a new method of systematic review designed for complex policy interventions. Journal of Health Services Research \& Policy. 10 (1_suppl), 21-34. http://dx.doi.org/10.1258/1355819054308530

3. Treagust, D., Harrison, A. (1999) The genesis of effective scientific explanations in the classroom. In J. Loughran, ed. Researching Teaching: Methodologies and practices for understanding pedagogy. Abingdon: Routledge, pp. 28-43. 


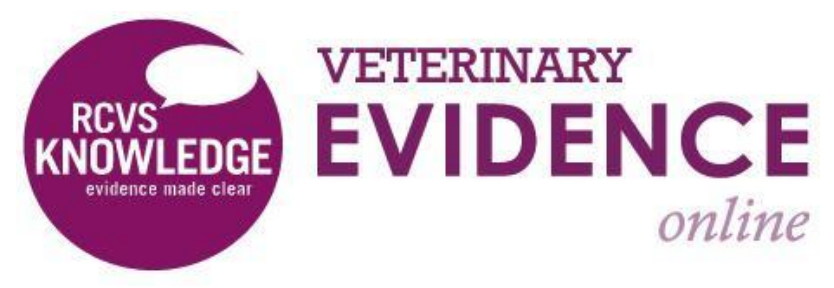

\begin{abstract}
Intellectual Property Rights
Authors of Articles submitted to RCVS Knowledge for publication will retain copyright

in their work, and will be required to grant to RCVS Knowledge a non-exclusive

license of the rights of copyright in the materials including but not limited to the right to publish, re-publish, transmit, sell, distribute and otherwise use the materials in all languages and all media throughout the world, and to license or permit others to do
\end{abstract}

so.

Veterinary Evidence and EBVM Network are RCVS Knowledge initiatives. For more information please contact us at editor@veterinaryevidence.org.

RCVS Knowledge is the independent charity associated with the Royal College of Veterinary Surgeons (RCVS). Our ambition is to become a global intermediary for evidence based veterinary knowledge by providing access to information that is of immediate value to practicing veterinary professionals and directly contributes to evidence based clinical decision-making.

www.veterinaryevidence.org

RCVS Knowledge is a registered Charity No. 230886. Registered as a Company limited by guarantee in England and Wales No. 598443.

Registered Office: Belgravia House 62-64 Horseferry Road London SW1P 2AF 